\title{
A oficina da história é como uma marcenaria
}

\author{
Gilmar Arruda*
}

\section{RESUMO}

Neste artigo comparo o ofício de marcenaria, suas formas de aprendizagem e regras de confiabilidade com o ofício do historiador, seu aprendizado e as regras de validação dos resultados. A intenção é reafirmar a história como um ofício com métodos, regras de execução e critérios de validação dos resultados.

Palavras-chave: história e historiadores, ofício da história, conhecimento histórico.

Aprendizes de historiadores e de marceneiros

Quando começamos a meditar sobre o tema do ofício do historiador, uma boa estratégia é pensar naqueles ofícios que possuem uma oficina, como uma marcenaria, madeiras, ferramentas, lixas, colas, serras, etc. Um lugar onde o profissional, o oficial, chega no começo do dia, abre a porta, liga as mácuinas, e começa a trabalhar. Talvez esta associação seja uma forma de dar tranqüilidade, certezas ao que fazemos quando nos nomeamos como historiadores. Nestes tempos que correm, ter uma oficina para abrir pela manhã, fechar para o almoço e, a tarde quando encerrar o expediente, ver os resultados concretos do trabalho, uma mesa, uma cadeira, ou mesmo somente as madeiras serradas e lixadas demonstrando objetivamente como está sendo construído o objeto, bem que poderia ser um bom refúgio nestes tempos de sobressaltos e dúvidas atrozes sobre os significados da nossa profissão, o nosso ofício.

Mas além do refúgio que esta comparação poderia criar, a associação com a atividade de um marceneiro também permite-nos comparar as formas de aprendizado da arte, como ele torna-se um aprendiz, um meio-oficial e, finalmente, um oficial de marcenaria.

\footnotetext{
* Professor do Departamento de História - Universidade Estadual de Londrina - e-mail-garruda@uel.br
} 
Aqui talvez um exemplo pessoal possa esclarecer melhor. Tive um vizinho, quando morava em Campo Grande-MS, que era marceneiro. Ele aprendeu com seu pai, que era paraguaio e dominava a arte usando antigas ferramentas, pouca cola, nenhum compensado ou "mdf". Desde cedo, começou, como parece ser a trajetória de todos, lixando as madeiras, depois passou a fazer os cortes brutos, aprendeu fazer encaixes, montar, dar acabamento, verniz, marchetaria, definir as madeiras - secas ou verdes, duras ou maleáveis, nomes, cheiros, etc e, finalmente, a desenhar, criando um estilo próprio, uma particularidade de acabamento. Finalmente, um dia, trouxe-me um cartão que dizia: Luiz Vegine, oficial de marcenaria. Ele havia aberto sua própria marcenaria.

Assim, um ofício foi transmito de uma geração para outra através da prática cotidiana, da observação, imitação, cópia e, finalmente, a originalidade do novo oficial. Um conhecimento adquirido através do contato com outros oficiais mais velhos. Nesta profissão, não é a única forma de se apreender, existem inclusive algumas, poucas, escolas para transmitir as artes do ofício. Mas o que faz um aprendiz transformar-se em um oficial, em artista, inaugurando um estilo, criando uma nova tradição é sem sombra de dúvida 0 talento individual, indivíduos talentosos, conforme diria José Carlos Reis (1999).

A comparação do trabalho do historiador com do marceneiro, poderá nos ajudar a perceber a nossa própria profissão. Como se apreende este ofício, existe uma maneira de transmiti-lo, o que se deve apreender para se tornar um historiador

Devemos pensar nos nossos passos, nas coisas que fazemos, escrevemos, procurando perceber quando e como teria começado o aprendizado, a entrada na oficina desta profissão, como aprendiz. Na maior parte das vezes e dos casos os aprendizes nunca se tornam mestres inaugurando uma oficina própria, um estilo próprio, etc. Claro que a posição de aprendiz é mais tranqüila, menos responsabilidade, basta ficar esperando as ordens do oficial, do mestre: corte aqui, lixe ali.. E, finalmente, observar o mestre fazer aquele acabamento, aquele detalhe de marchetaria, aquele encaixe rabo de andorinha perfeito, que quase não precisa de cola para juntar as peças.

Na maior parte dos aprendizes, dos que se lançam na aventura profissional, falta experiência, sabedoria e, quem sabe, talento, para aceitar tal mérito É difícil saber quando se pode abrir a própria marcenaria. No trabalho do historiador somente os outros, a comunidade dos profissionais é que poderão dar o reconhecimento para isso. 
Mas para abrir uma oficina própria é preciso saber desenhar os móveis, dominar todos os passos da arte, é preciso, portanto, saber como se aprende estes passos e como podem ser dados. É preciso dominar as técnicas do ofício do historiador.

\section{A minha experiência como aprendiz}

Talvez seja importante, nesta discussão, incluir um pouco de minha própria experiência para discutir o ofício de historiador. Comecei na oficina, a minha graduação, em Campo Grande, nas Faculdades Católicas Salesianas de Mato de Mato Grosso do Sul, antiga FUCMT, hoje Universidade Dom Bosco. Láliz a licenciatura, em três anos, sim, uma licenciatura curta. Isto é importante de dizer pois neste momento em que se discute reforma curricular existe uma certa pressão, ou melhor, uma certa interpretação de que sem a habilitação bacharelado não seria possível desenvolver pesquisas. Neste caso, posso afirmar que a pesquisa pode e acontece nos cursos de licenciatura.

Comecei trabalhando nesta oficina lixando móveis, ou melhor, fazendo levantamento de fontes. Embora tenha nascido no interior de São Paulo, minha família foi tangida para o oeste por conta da crise do final dos anos 70 . Penso que uma das formas de me encontrar, de buscar um sentimento de pertencimento ao novo local foi buscar o seu passado. Este aqui é dos principais problemas que áfetam o praticante da oficina: identidade versus universalidade. Comentarei mais para frente esta questão.

Meu primeiro tema de pesquisa, ou a minha primeira vontade de pesquisar esteve associada a necessidade do homem encontrar no passado pontos de identidade. O tema era a erva mate no Mato Grosso do Sul. 0 início deu-se exatamente num dos locais preferidos dos oficiais da história: a biblioteca. Apesar da Faculdade ser privada possuía uma boa biblioteca e lá comecei a procura pelos livros que pudessem informar sobre a erva mate. Não demorou muito para perceber que havia poucos estudos, ou melhor, havia um feito em 1925 por um conhecido historiador e geógrafo do Mato Grosso - Virgilio Correa Filho. Além disso, não se encontrava cópias deste livro. De cara a pesquisa estaria encerrada, se não fosse uma professora de História. do Brasil que sugeriu fazer uma pesquisa de fontes, sim um arrolamento, um levantamento documental. 
A minha primeira tarefa como aprendiz foi, portanto, com a própria matéria prima do historiador: as fontes. Talvez ainda num sentido bastante positivista, mas principalmente, grande lição, que sem fontes não existe a possibilidade da história. Foi a partir dos restos deixados pelo passado que comecei a reconstruir uma das facetas da exploração dos ervais no sul de Mato Grosso do Sul.

Mas uma vez despertado para a vontade de desvendar o passado, alguns diriam que se trata de uma ambição tola, impossivel, o contato com as fontes não era suficiente, faltava-me uma regra, um método, uma formação teórica mais aprofindada que pudesse dar conta da leitura daquelas fontes levantadas. A pós-graduação, muito mais do que a formalização de estudos serviu-me para entrar em contato com as "novidades" no campo da historiografia os grupos de estudos, jovens pesquisadores, ou recém doutores que por lá andavam traziam as "últimas": lá eu conheci o chamado "marxismo inglês" que me possibilitou escrever a minha dissertacäo. Uma história dos trabalhadores dos ervais sul-matogrosenses.

E importante destacar que não só a renovação historiográrica foi importante, mas o estudo dos chamados clássicos, através dos professores mais antigos, que deram uma enorme ajuda na formação inicial da pesquisa. Transformação com conservação, segundo as palavras de José Carlos Reis. A historiografia forma-se não só com destruição, mas com incorporaçăo, conservação e superação. (1999)

As escolhas teóricas, metodológicas e historiográficas não são aleatórias ou como escolha de produtos em um supermercado. As escolhas estão profundamente associadas ao sujeito do conhecimento - o oficial historiador - como indivíduo imerso em seu tempo socialmente e subjetivamente.

A conquista do oeste: imaginário e classes populares na ocupação do oeste. Era este o título inicial do projeto de doutoramento. Ele diz muito sobre as intenções e perspectivas de leituras sobre o passado. O que era uma pesquisa sobre um passado para criar um sentimento de pertencimento durante o mestrado havia se transformado em uma pesquisa sobre o meu próprio passado. As classes populares não eram para mim uma abstração conceitual, eu a percebia como algo concreto material e culturalmente. 0 processo histórico do título não era uma terra estrangeira. A origem do tema estava ligada a própria 
memória familiar. A minha família havia vivido no 'olho do furação", o processo de incorporação a circuito de circulação de mercadorias, de todo o oeste do Estado de São Paulo, norte do Estado do Paraná, etc, a partir do início do século XX. Agora eu, aprendiz de historiador, freqüentando as melhores oficinas do país procurava transformar as lembranças em uma sólida mesa historiográfica.

$\Lambda$ experiência da pesquisa é algo que se aprende fazendo e estudando os métodos. Ao apresentar uma primeira versão de um dos capítulos da tese, meu orientador - oficial historiador - disse-me: Gilmar, este texto é apenas suas lembranças e as de sua família, é apenas um relato, para se tornar história necessita uma lógica de demonstração, evidências e explicação histórica. Foi uma enorme ducha fria, aquilo que eu pensava ser a parte mais original e importante da pesquisa não passava de apenas um relato. Mas aí aparece a importância do orientador, do mestre marceneiro que corrige e orienta 0 aprendiz. Recomendou-me que voltasse a ler Raymond Williams, autor que talver tenha levado até as úlimas consequiências a idéia de cultura como experiência herdada e adquirida, para ele este campo é uma terra fronteiriça: "..é aquela terra fronteiriça em que muitos de nós vivemos: entre a tradição e a instrução, entre o trabalho e as idéias, entre o apego ao torrão natal e a vivência das mudanças". (1990, p. 269).

A experiência de pesquisa do orientador tornou-se fundamental para que eu não abandonasse a perspectiva tomada, mas sim conseguisse encontrar o método, a reflexão teórica adequada para solucionar o problema de transformar um relato - independentemente de sua origem - em uma evidência concreta de um processo histórico vivido por milhares de pessoas.

A lição que aprendi é que nenhuma pesquisa origina-se do vazio, nem é produzida individualmente. A rede de trocas e discussões - entre pares e entre autores - é fundamental para transformar um simples desenho - o projeto em algo concreto, em explicação histórica. Ainda mais, que a experiência acumulada na oficina, representada pelos historiadores mais velhos e experientes, é imprescindivel para não ter que reaprender a utilizar as ferramentas a cada nova geração de aprendizes. E por fim, nem sempre temos talento para sermos oficiais, a arrogância apenas quebra a serra, ou corta a mầo. 
As ameaças de falência da nossa oficina

A comparação do nosso ofício com a aprendizagem de marceneiros, em uma oficina concreta, permite ver que existem muitas semelhanças quanto a formação do oficial na área de história.

Existe um conhecimento que pode ser transmitido a novas gerações de historiadores, existe um local para se trabalhar, mesmo que a nossa oficina seja mental; há uma matéria prima de nossa profissão, os documentos; é necessário prática - levantamento, bem como técnica - metodologia para começar a burilar com a madeira-documento, e também um visão geral do objeto, no nosso caso isto se aproximaria da teoria, a junção das partes.

Vimos também que a transmissão deste conhecimento possui uma formalização através dos cursos de graduação e pós-graduação, mas depende de um contato maior com os mestres do ofício, os orientadores e historiadores consayrados, os clássicas. Podemos dizer que a transmissão deste conhecimento os segredos do ofício - não acontece somente nos "bancos escolares", através da grade curricular. Frequientar a graduação é necessário, mas não suficiente. Assim como para apreender a arte da marcenaria é necessário frequientar a oficina mas isto näo é suficiente, é preciso por a mão na madeira. A práaica, neste caso, assim como na arte de ensinar, é fundamental e ela ocorre nos espaços-oficina da nossa profissäo: na gradução e pós-graduação, nas discussc̃es sobre teoria-metodologia; nos depósitos de matéria prima - arquivos, museus; nos simpósios e congressos etc

A comparação, por fim, aponta a existência de um corpo sistematizado de teoria, metodologia e práticas, uma tradição, que permitem verificar a qualidade do produto, a excelência do oficial. No caso dos historiadores, temos a tradição baseada na supremacia da evidência e nas regras de controle da pesquisa e da exposição. A disciplina histórica é essencialmente realista, no sentido da existência real do passado. 0 conjunto de regras e procedimentos da oficina da história faz parte da tradição do conhecimento cientííico, sistematizado nos últimos 100 anos.(Falcon, 1996).

Mas apesar desta tradição e de seus métodos estabelecidos tem crescido os rumores de falência da oficina. Dizem que os móveis são de baixa qualidade, que não param de pé, desmancham com a maior facilidade. Outros afirmam que os móveis não servem para nada e chegam, até, a comentar que a oficina 
é uma grande arapuca, pois afirma que pode fazer um trabalho concreto, desenha um grande e bonito produto, mas no final não entrega nada, apenas ilusão. Assim o produto da oficina dos historiadores está sob su.speita cerrada e a oficina pode ser fechada.

Já podemos fazer um diagnóstico desta descrença quanto ao funcionamento da oficina. Pode-se dividir em duas vertentes: a primeira mais antiga vem demonstrando, desde já os anos 50, o desaparecimento da necessidade de usar móveis, isto é, do passado na sociedade contemporânea. Isto não significa que critiquem os métodos da produção do conhecimento sobre o passado, mas constatam a gradual perda do sentido histórico nos tempos atuais. Fstaríamos vivendo, em termos de percepção, um eterno presente. Neste grupo, encontramos pensadores como Hannah Arendt, Cristopher Lasch, Eric Hobsbawm. Vamos a eles:

Nos anos 50, Hannah Arendi jáa afirmava:

O declínio contemporâneo do interesse pelas humanidades e em especial pelo esiudo da História, aparentemente inevi-tável em todos os países modernizados [ deve-se ao fato de que] Podemos fazer no domínio físico-natural aquilo que pensávamos poder fazer apenas no domínio da História. Começamos a agir sobre a natureza como costumávamos agir sobre a história. (ARENDT,1988:89)

Nos anos 70, Christopher Lasch

Uma sociedade que faz da "nostalgia" uma mercadoria co-mercial [ vide novelas de épocal tendo trivializado o passa-do, ao igualá-lo a estilos ultrapassados de consumo, modas e atitudes, dos quais abriram mão, as pessoas, hoje em dia, ressentem-se de qualquer um que recorra ao passado para séries discussões sobre as condições contemporâneas, ou que tente usar o passado como um padrão com que julgalr o presente(LASCH, 1983:15)

Nos anos 90, Hobsbawm

A destruição do passado - ou melhor, dos mecanismos sociais que vinculam nossa experiência pessoal à das gerações passadas - é um dos fenômenos mais 
característicos e lúgubres do final do século XX. Quase todos os jovens de hoje crescem numa espécie de presente contínuo, sem qualquer relação orgânica com o passado público da época que vivem. Por isso, os historiadores, cujo ofício é lembrar o que os outros esquecem, tornam-se mais, importantes do que nunca no fim do segundo milênio (Hobsbawm, 1995, 13).

Ou mais perto de nós, espaço temporalmente, Francisco Falcon:

Prefiro, portanto partir da hipótese de que a crise na bistória é real e tem como uma de suas características ou efeitos a incidência sobre o processo de produção do conhecimento histórico - a escrita da bistória-, envolvendo assim o historiador e o seu discurso (Falcon, 1996:17)

Wstes intelectuais argumentam desde pelo menos a metade do século passado que esta em curso uma mudança da relação da sociedade com o seu passado, isto é, pelo menos da sociedade ocidental, tributária do mundo surgido a partir de Grécia e Roma. Como a ciência histórica, que é uma das formas de produção de sentido sobre o passado, mais estabelecida e aceita entre nós, é também en seus métodos e procedimentos fruto do seu tempo, passou a enfrentar várias criticas e reparos quanto a sua validade. Estaria instalada assim a crise na oficina da história e, não mais apenas, a crise da história, como diz Francisco Falcon.

Aqui encontramos a segunda vertente dos que anunciam a falência da oficina. Neste caso, declaram a falência e a falsidade do resultado do trabalho dos historiadores e não apenas de discussões sobre transformações internas aos procedimentos admitidos como essenciais para o desenvolvimento e produção da historiografia. Seria desnecessário dizer que esta forma de produção, uma vez que sempre se admitiu largamente que o conhecimento histórico é fruto de seu tempo, ou seja, as ciências, quaisquer que sejam elas, são históricas.

Esta vertente de crítica admite mesmo a possibilidade de falência de uma sociedade baseada na razão, na possibilidade da inexistência mesma de uma razão que possa informar os homens sobre suas condutas.

E claro que isto afeta diretamente nosso ofício - tanto sua face de pesquisa quanto a de ensino não apenas para assegurar-nos emprego e importância 
social, sempre é possivel vender pastéis na feira ou tornar-se cronista, comentarista, romancista e marceneiro.

A face mais visivel desta crise parece estar na discussão sobre o estatuto tanto do passado quanto do conhecimento obtido através da operação historiográfica. A versão mais radical pode ser percebida em um livro de Keith Jenkins, "A história repensada" traduzido em 2001, há pouco tempo portanto.

Nele Jenkins afirma categoricamente que a história seria um dos muitos discursos formulados sobre o mundo e de que não haveria possibilidade de afferimos, sob nenhum critério de validação, as afirmações oriundas do discurso historiográfico, tratando-se, portanto, apenas de narrativas, tal qual o passado chega até nós. Seria mesmo impossivel obter algum conhecimento do passado uma vez que o passado já não existiria, porém "...ainda vemos historiadores tentarem invocar ante os nossos olhos o espectro do passado real, um passado objetivo sobre o qual os relatos desses bistoriadores seriam precisos e até verdadeiros, na acepção mais ampla da palavra"(p.30). A história seria, portanto, apenas um relato e toda pretensão de verdade seria apenas um recurso do poder ou ideológico. Os historiadores apenas pretenderiam nos convencer que são objetivos.

Não é preciso ir muito longe para perceber que se trata de um destes sintomas apontados pelos autores apontados acima: uma descrença completa na possibilidade da razão - do projeto iluministalracionalista - em conhecer o mundo. A ciência seria apenas resultado de uma operação intelectual e atenderia as demandas do poder, qual poder não sabemos.

Seria possível um mundo sem passado, talvez não, mas e sem historiadores? Para Jenkins talvez sem historiadores baseados em uma tradição científica racionalista. Se o resultado da operação historiográfica não serve mais para estabelecer um sentido racional para o passado, mesmo que parcial e limitado ao seu tempo, para que então serviria o discurso sobre o passado feito por qualquer projeto de história/conhecimento, mesmo que narrativo, pensado enquanto texto ficcional, igual a qualquer outro relato?

Esta perspectiva sobre o fazer do historiador não implica apenas em uma crise interna na definição sobre o estatuto da historiografia, do conhecimento histórico ou dos critérios de definiçã̃o de identidade para um texto como histórico ou não mas, principalmente, no papel social do oficio do historiador. Mesmo 
que abandonemos qualquer ilusão racionalista sobre a virtus política racional do ser humano, da possibilidade de ação racional na esfera pública do homem, ainda continuaremos vivendo em sociedade e isto implica em encontrar fórmulas de evitar a barbárie, até agora evitada, talvez, pela razão.

Isto que dizer que a crítica ao modelo racionalista de apreensão da realidade não é apolítico, ou apenas intelectual, como se em algum momento do mundo pensarlescrever fosse apenas um exercício intelectual. Ele envolve a percepção e posicionamento do profissional frente a realidade que o cerca. Neste sentido, quero agora pensar nas implicações políticas em admitir ou praticar uma operação historiográfica baseada no realismo\racionalismo.

Os riscos de uma história como ficção.

Jonh Lewis Gaddis(2003), retoma a tradição iniciada com Marc Bloch, depois Edward Carr, em aproximar a história do campo científico, de um conjunto de conhecimento científico que não pode reproduzir seus experimentos em laboratórios, devido a escala de tempo ou espaço envolvida na observação como a geologia, a física teórica, etc. Gaddis, afirma que nenhum geólogo observou "empiricamente', em seu laboratório, o movimento das placas tectônicas, no entanto, a teoria do movimento das placas é largamente aceito pela comunidade internacional. Para Gaddis, os geólogos trabalham com estruturas existentes para tentar entender o processo ou processos que levaram ao estabelecimento das estruturas, partem portanto de questões do presente. Assim também o historiador, parte de questões do presente, formuladas para estruturas existentes na atualidade para tentar explicar os processos de formação destas mesmas estruturas.

Mas outro aspecto significativo nos argumentos de Gaddis é a que a ciência tem uma "qualidade que a distingue de quaisquer outros métodos de pesquisa: ela mostrou-se mais eficaz de obier consenso na comprovação de resultados entre culluras de diferentes linguas, e entre observadores extremamenie diversos. "( produzir conhecimentos e resultados, como ler entranhas de animais, ler a sorte através da palma da mão, mas a possibilidade de se chegar a consenso nestes métodos é duvidosa. A vantagem da ciência é ter a possibilidade de 
"prover um consenso de opinião racional sobre um campo o mais amplo possivel" (p. 54)

A possibilidade em "consenso racional amplo" tem o mesmo sentido de Hobsbawm quando fala de universalidade do conhecimento. Esta é a única possibilidade de escaparmos das armadilhas do "reforço das identidades" colocadas no caminho do aprendiz de historiador. Quanto mais próximo espaço-temporalmente o aprendiz estiver de seu tema, mais riscos ele correrá em produzir uma " história de identidades".

A questão que se coloca para os aprendizes de ofício é como se posicionar frente ao mundo contemporâneo: aceitar a sua aparência de caos e aderir ao nihilismo ou recuperar para a oficina os seus atributos de racionalidade? 0 que está colocado para os que lidam com o passado e com a história é a alternativa entre um mundo que ainda possa ser governado pela razão e um mundo que se torna cada vez mais completamente caótico e irracional.

Nestes tempos de aparente caos, de impossibilidade de um futuro, abandona-se a possibilidade de passado e a irresponsabilidade com a continuidade, com a herança das gerações passadas, ameaça as gerações futuras. É necessário discutir mais o papel que o ofício de historiador e professor de história possui no presente, agora ainda mais, por estar ameaçado pela onda irracionalista.

Nesta crise da sociedade contemporânea, que ameaça a própria existência da vida na terra, tantas vezes denunciada por movimentos sociais ecológicos, um dos seus alspectos mais lúgebres seria a perda dos sentido histórico, como apontou Hobsbawm. Da necessidade mesmo de estudar o passado como "metron", como experiência, como forma de estabelecimento de continuidade e responsabilidade das gerações atuais com os que virão. Este é o papel que resta aos profissionais e aprendizes da arte da história.

\section{Bibliografia}

ARENDT, Hannah. A condição bumana. Rio de Janeiro: Forense Universitúria, 1983. ARENDT, Hannah. Entre o passado e o futuro SP: Perspectiva, 1988

FALCON, Francisco J. C. A identidade do historiador. Esiudos Históricos. Rio de Janeiro, $v^{0} .09,1996$. p. 07-31 
GADDIS, John. Paisagens da bistória: como os bistoriadores mapeiam o passado. Rio de Janeiro: Campus, 2003.

HOBSBAWM, Eric. Sobre a bistória. São Paulo: Cia as Letras: 1998.

JENKINS, Keith. A bistória repensada. São Paulo: Contexto, 2001.

LASCH,Christopher. A cultura do narcisismo; a vida americana numa Era de Esperança em declinio. RJ: Imago, 1983

REIS, José Carlos. As identidades do Brasil: de Varnbagen a FHC. $2^{2}$ ed. Rio de Janeiro: Fundação Getulio Vargas Ed. 1999.

WILLIAMS, Raymond. O campo e a cidade. São Paulo: Cia das Letras. 1990.

\title{
our workshop is as a joinery
}

\begin{abstract}
In that article I compare the historian's trade with the joiner's trade, theirs forms and rules of apprenticements. I compare too the forms we can know about realible of objects wich results theirs works. My intention is proved that history is a science not a fiction or a novel.
\end{abstract}

Key words: history historians, historical knowledge, workshop history. 